\title{
Association Between Low Serum Testosterone and the Development of Metabolic Syndrome in Elderly Taiwanese Men
}

This article was published in the following Dove Press journal: Diabetes, Metabolic Syndrome and Obesity: Targets and Therapy

\author{
Shang-Rong Zhong' \\ Han-Hsuan Yang ${ }^{1-3}$ \\ Cheng-Hsi Liao ${ }^{4-7}$ \\ Deng-Ho Yang 5,6,8,9 \\ Shih-Kai Tu ${ }^{1,5}$ \\ Chia-Lien Hung ${ }^{6}$ \\ Chun-Cheng Liao (iD) 1,5,6 \\ 'Department of Family Medicine, \\ Taichung Armed Forces General Hospital, \\ Taichung, Taiwan; ${ }^{2}$ Department of \\ Occupational Medicine, Taichung \\ Veterans General Hospital, Taichung, \\ Taiwan; ${ }^{3}$ School of Professional Education \\ and Continuing Studies, National Taiwan \\ University, Taipei, Taiwan; ${ }^{4}$ Division of \\ Urology, Department of Surgery, \\ Taichung Armed Forces General Hospital, \\ Taichung, Taiwan; ${ }^{5}$ School of Medicine, \\ National Defense Medical Center, Taipei, \\ Taiwan; ${ }^{6}$ Department of Medical \\ Education and Research, Taichung Armed \\ Forces General Hospital, Taichung, \\ Taiwan; ${ }^{7}$ Graduate Institute of Biomedical \\ Science, China Medical University, \\ Taichung, Taiwan; ${ }^{8}$ Division of \\ Rheumatology/Immunology/Allergy, \\ Department of Internal Medicine, \\ Taichung Armed Forces General Hospital, \\ Taichung, Taiwan; ${ }^{9}$ Department of \\ Medical Laboratory Science and \\ Biotechnology, Central Taiwan University \\ of Science and Technology, Taichung, \\ Taiwan
}

Correspondence: Chun-Cheng Liao Email milkbottle97@yahoo.com.tw
Purpose: To assess the association between serum testosterone (T) and metabolic syndrome (MS) in different age groups in Taiwanese men.

Materials and Methods: Male participants, regardless of age or any underlying disease, were identified from MJ Health Screening Center in Taiwan from 2007 to 2016 for this crosssectional study. They were divided into three groups according to age, and further classified according to MS diagnosis. Basic patient characteristics with relevant parameters were obtained. One-way ANOVA of mean $\mathrm{T}$ values between different numbers of measures that exceeds the cut-off values of MS components was performed to assess the relationship of $\mathrm{T}$ and MS. Logistic regression analysis was also used to estimate the risk for MS with each increment in T, age, and BMI.

Results: A total of 4,931 men were included. The MS group had significantly lower serum $\mathrm{T}$ levels compared to the non-MS group in each age group. The one-way ANOVA found the mean value of T was significantly higher in patients without MS component $(6.19 \pm 2.12 \mathrm{ng} /$ $\mathrm{mL}$ ) than those with 1-5 MS components (with one MS component: $5.48 \pm 2.13 \mathrm{ng} / \mathrm{mL}$, two MS components: $4.93 \pm 2.03 \mathrm{ng} / \mathrm{mL}$, three MS components: $4.37 \pm 1.60 \mathrm{ng} / \mathrm{mL}$, four MS components: $4.13 \pm 2.89 \mathrm{ng} / \mathrm{mL}$, five MS components: $3.74 \pm 1.27 \mathrm{ng} / \mathrm{mL}$, and $P<0.001$ ). There was no significant difference between the patients with three components and the patients with four or five components. Logistic regression models with age stratification showed $\mathrm{T}$ with lower odds ratio (OR) for MS after adjusting for BMI in those $\geq 65$ years old $(\mathrm{OR}=0.693 ; \quad 95 \% \quad \mathrm{CI}=0.559-0.858 ; \quad P<0.001) ; \quad 50-64$ years old $\quad(\mathrm{OR}=0.868 ; \quad 95 \%$ $\mathrm{CI}=0.802-0.940 ; P<0.001)$ and $<50$ years old $(\mathrm{OR}=0.810 ; 95 \% \mathrm{CI}=0.758-0.865 ; P<0.001)$. Conclusion: Lower serum $\mathrm{T}$ was strongly associated with MS, with the predictive value increasing with age in Taiwanese men.

Keywords: testosterone, metabolic syndrome, hypogonadism, insulin resistance

\section{Introduction}

Adult onset hypogonadism, defined by the Sexual Society of North America, is characterized by deficiency of testosterone $(\mathrm{T})$ with variable and nonspecific symptoms and signs, like decreased sexual function and desire, fatigue, depression, muscle weakness, and increased body fat. ${ }^{1,2}$ Hypogonadism can be further classified into primary or secondary hypogonadism depending on whether the aberrancy is located in the testes or pituitary gland, respectively. On the other hand, male menopause, or aging-related hormonal changes, is a natural course in men. Unlike menopause in women, men do not usually experience dramatic changes during this 
stage of life considering that the decline in sex hormone occurs gradually over years without definite consequences. The Hypogonadism in Males (HIS) study in 2006 revealed a $38.7 \%$ crude prevalence of hypogonadism (defined as total testosterone $\mathrm{T}<300 \mathrm{ng} / \mathrm{dL}$ ) in men aged $\geq 45$ years. $^{3}$ Another study from the Boston Area Community Health survey focusing on symptomatic androgen deficiency in men (total $\mathrm{T}<300 \mathrm{ng} / \mathrm{dL}$ or free serum $\mathrm{T}<5 \mathrm{ng} / \mathrm{dL}$, plus $\geq 3$ symptoms) aged 30-70 years found a prevalence of $5.6 \%{ }^{4}$ Sex hormone-binding globulin (SHBG), an androgen-binding glycoprotein produced mostly in the liver, also plays an essential role in the related metabolism. Basically, it increases gradually with aging and thus allows less active $\mathrm{T}$ in the blood stream. However, in obese men, the SHBG level is lower compared to other non-obese men despite age. ${ }^{5}$ It is also associated with mortality in men with diabetes, and decreased SHBG are linked to insulin resistance, and the development of type 2 diabetes. ${ }^{6,7}$

Metabolic syndrome (MS) comprises several simultaneously occurring elements that increase the risk of cardiovascular and cerebrovascular complications, as well as type 2 diabetes mellitus. There are several definitions made around the world with various criteria, like the International Diabetes Federation, American Association of Clinical Endocrinologists, World Health Organization and so on, resulting in difficulty in integrating researches in this field. In Taiwan, we adopted the one similar to the 2005 American Heart Association/National Heart, Lung, and Blood Institute (AHA/NHLBI) guideline, and it is also an important part in our adult health checkup. Moreover, MS has been clearly associated with insulin resistance, obesity, and disruption of the normal physiological balance. ${ }^{8}$ Notably, studies had found that MS was present across various age groups throughout the US between 2003 and 2012, with prevalence rates increasing with age (8.3\% in those aged from $20-39$ years; $46.7 \%$ in those aged $\geq 60$ years). ${ }^{9}$

The aforementioned sex hormone, $\mathrm{T}$, plays a vital role in the male reproductive system, as well as in certain human metabolic mechanisms. However, as men age, serum T concentrations inevitably decline, potentially causing several physiological and psychological changes, including decreased sexual function, muscle development, mental function, erythropoiesis, and bone mineral density of elderly men. ${ }^{10}$ Several recent studies have indicated a strong relationship between T and MS, suggesting the essential role of $\mathrm{T}$ in glucose and lipid homeostasis. ${ }^{11-13}$ One meta-analysis found evidence with $\mathrm{T}$ in improving central obesity, insulin resistance, diabetes control, and peripheral oxygenation in men with late-onset hypogonadism. ${ }^{14}$ Nevertheless, further investigations are still required to determine the definite mechanism and establish clear causality. T replacement therapy has also been suggested as a potential treatment after considering risks and benefits. However, studies have provided conflicting results, while strong evidence regarding its treatment efficacy is still absent. ${ }^{15-17}$

The current study therefore aimed to analyze the association between serum total $\mathrm{T}$ level and the incidence of MS among adult Taiwanese men, providing statistical results for the Asian population. Moreover, we identified a target range of men that required $\mathrm{T}$ level monitoring during regular medical follow-up and provided them with patient-centered therapy, as well as information regarding the latest evidence on hormone replacement therapy.

\section{Materials and Methods}

\section{Study Population}

This cross-sectional study retrieved data from a large private health examination institute (MJ Health Screening Center) in Taiwan from 2007 to 2016. Given that this institute provided self-paid health examination services in major districts in Taiwan with general payment around 200-730 USD (about 17 USD specifically on serum testosterone), the demographic characteristics of the included patients were believed to be similar to those of the general Taiwanese population. A total 4,931 participants, regardless of age or underlying disease, were identified during the designated time period. Participants who had insufficient data for the evaluation of the MS status, serum testosterone, or female gender were subsequently excluded. All participants were divided into three groups according to age (group 1, $\mathrm{n}=3,066,<50$ years old; group $2, \mathrm{n}=1,384,50-64$ years old; and group $3, \mathrm{n}=216, \geq 65$ years old) and further classified according to MS diagnosis (Non-MS and MS; Non-MS in group $1, \mathrm{n}=2,430$; MS in group $1, \mathrm{n}=636$; Non-MS in group 2, $\mathrm{n}=988$; MS in group 2, $\mathrm{n}=396$; Non-MS in group 3, $\mathrm{n}=139$; MS in group $3, \mathrm{n}=77$ ). The age range in group 1 was determined as other examination and immunization policies provided by our healthcare system, like the annual influenza vaccine, screening of the colon-rectal cancer and self-paid zoster vaccine, which are all 50 years old. We therefore defined those aged less than 50 as group 1, regarding 50 years old as the time that people started to pay more attention on their health. The second age point, 65 years old, 
was set in accordance with our free health checkup schedule in Taiwan.

All data used in this research were authorized by and received from the MJ Health Research Foundation (Authorization Code: MJHRF2019016A). Any interpretations or conclusions presented in this paper do not represent the views of the MJ Health Research Foundation. All participants in the research have given written informed consent before the health examination to authorize the data analysis. Personal identification data was removed in the MJ Health Research Foundation, so the participants remained anonymous during the whole research process. The detail of the study population and data collection is described and reported elsewhere. ${ }^{18}$

\section{Definition of Metabolic Syndrome, Waistline, and Body Mass Index (BMI)}

Clinical data related to the definition of MS defined by the Ministry of Health and Welfare of Taiwan, such as blood pressure, waistline, high-density lipoprotein (HDL), triglycerides (TG), and fasting blood sugar (FBS) were collected. Chemiluminescent micro-particle immunoassay (ARCHITECT i2000) was used for measuring T; Homogeneous Direct method (TOSHIBA C8000) for HDL-cholesterol; GPO-POD-ESPT method (TOSHIBA C8000) for TG; and HK.G-6-PD.NADP method (TOSHIBA C8000) for FBS. The definition and diagnosis of MS, as well as cutoff values for each parameter, were based on the 2005 AHA/NHLBI guideline. ${ }^{19}$ A diagnosis of MS was confirmed when more than three of the five following criteria were satisfied: 1) obesity with a waistline $\geq 90 \mathrm{~cm}$; 2) $\mathrm{TG} \geq 150 \mathrm{mg} / \mathrm{dL}$; 3) HDL $<40 \mathrm{mg} / \mathrm{dL}$; 4) systolic blood pressure (SBP) $\geq 130$ $\mathrm{mmHg}$ or diastolic blood pressure (DBP) $\geq 85 \mathrm{mmHg}$; and 5) FBS $\geq 100 \mathrm{mg} / \mathrm{dL}$.

The waistline is measured in the middle of the top of the hip bone and the bottom of ribs, without clothing that might interfere with measurements. The BMI is defined as the body mass (in kilograms) divided by the square of the height (in meters).

\section{Statistical Analysis}

Independent $t$-test was applied for analyzing the MS diagnosis (Non-MS and MS). Mean values and standard deviation for age, BMI, waistline, SBP, DBP, HDL, TG, FBS, and $\mathrm{T}$ were calculated for age stratification (Table 1). The One-way ANOVA with post-hoc Scheffe Method was applied for comparing the means of $\mathrm{T}$ among the numbers of MS (Figure 1). The logistic regression model was applied for analyzing the relationship between the MS diagnosis groups after adjusting for the factors of $\mathrm{T}$, BMI, and age (Table 2). Two-sided $P<0.05$ was taken to indicate statistical significance. SPSS 26.0 was used for statistical analysis.

Table I Patient Characteristics of the Participants in Different Age Group with or Without MS

\begin{tabular}{|c|c|c|c|c|c|c|c|c|c|}
\hline & \multicolumn{3}{|c|}{ Age $<50(n=3,066)$} & \multicolumn{3}{|c|}{ Age $=50-64(n=1,384)$} & \multicolumn{3}{|c|}{ Age $\geqq 65(n=216)$} \\
\hline & $\begin{array}{l}\text { Non-MS } \\
(n=2,430)\end{array}$ & MS (n=636) & $P$ & $\begin{array}{l}\text { Non-MS } \\
(n=988)\end{array}$ & MS (n=396) & $P$ & $\begin{array}{l}\text { Non-MS } \\
(n=139)\end{array}$ & MS (n=77) & $P$ \\
\hline Age & $38.8 \pm 6.7$ & $40.1 \pm 5.9$ & $<0.001 * * *$ & $55.8 \pm 4.4$ & $55.7 \pm 4.4$ & 0.703 & $70.9 \pm 4.7$ & $71.4 \pm 4.5$ & 0.472 \\
\hline BMI & $23.9 \pm 3.1$ & $28.2 \pm 3.7$ & $<0.001 * * *$ & $23.9 \pm 2.5$ & $27.1 \pm 2.8$ & $<0.001 * * *$ & $23.7 \pm 2.7$ & $26.7 \pm 2.4$ & $<0.00 I^{* * * *}$ \\
\hline WC & $81.6 \pm 7.6$ & $92.8 \pm 8.7$ & $<0.001 * * *$ & $82.5 \pm 6.8$ & $92.2 \pm 7.3$ & $<0.001 * * *$ & $84.1 \pm 7.4$ & $93.5 \pm 6.2$ & $<0.00 I^{* * * *}$ \\
\hline SBP & $115.9 \pm 12.5$ & $128.0 \pm 14.3$ & $<0.001 * * *$ & $118.2 \pm 14.5$ & $131.7 \pm 15.7$ & $<0.001 * * *$ & $125.4 \pm 17.6$ & $138.7 \pm \mid 4.3$ & $<0.001 * * *$ \\
\hline DBP & $74.5 \pm 9.2$ & $83.2 \pm 9.9$ & $<0.001 * * *$ & $77.4 \pm 9.6$ & $84.9 \pm 9.8$ & $<0.001 * * *$ & $75.4 \pm 8.9$ & $81.3 \pm 7.7$ & $<0.00$ I $^{* * * *}$ \\
\hline $\mathrm{HDL}$ & $53.1 \pm 10.9$ & $45.1 \pm 8.9$ & $<0.001 * * *$ & $57.9 \pm 12.2$ & $45.8 \pm 9.9$ & $<0.001^{* * * *}$ & $55.6 \pm 12.4$ & $47.96 \pm 10.8$ & $<0.00 I^{* * * *}$ \\
\hline TG & $115.2 \pm 71.9$ & $228.5 \pm 166.9$ & $<0.001 * * *$ & $|I| . \mid \pm 57.6$ & $194.9 \pm 100.4$ & $<0.001^{* * * *}$ & $93.7 \pm 41.3$ & $|83.1 \pm| \mid 5.5$ & $<0.00 I^{* * * *}$ \\
\hline FBS & $100.2 \pm 12.5$ & $113.9 \pm 32.6$ & $<0.001 * * *$ & $107.1 \pm 19.9$ & $120.7 \pm 27.5$ & $<0.001 * * *$ & $109.3 \pm 20.6$ & $120.6 \pm 33.4$ & $0.002^{* *}$ \\
\hline $\mathrm{T}$ & $5.4 \pm 2.0$ & $4.2 \pm 1.8$ & $<0.001 * * *$ & $5.6 \pm 2.4$ & $4.4 \pm 2.5$ & $<0.001^{* * * *}$ & $6.1 \pm 3.1$ & $4.3 \pm 1.6$ & $<0.001 * * * *$ \\
\hline
\end{tabular}

Note: $* * P<0.01 ; * * *<<0.001$.

Abbreviations: MS, metabolic syndrome; BMI, body mass index $\left(\mathrm{Kg} / \mathrm{m}^{2}\right)$; WC, waist circumference ( $\mathrm{cm}$ ); SBP, systolic blood pressure (mmHg); DBP, diastolic blood pressure $(\mathrm{mmHg})$; HDL, high-density lipoprotein $(\mathrm{mg} / \mathrm{dL}) ; \mathrm{TG}$, triglyceride $(\mathrm{mg} / \mathrm{dL}) ; \mathrm{FBS}$, fasting blood sugar $(\mathrm{mg} / \mathrm{dL}) ; \mathrm{T}$, testosterone $(\mathrm{ng} / \mathrm{mL})$. 


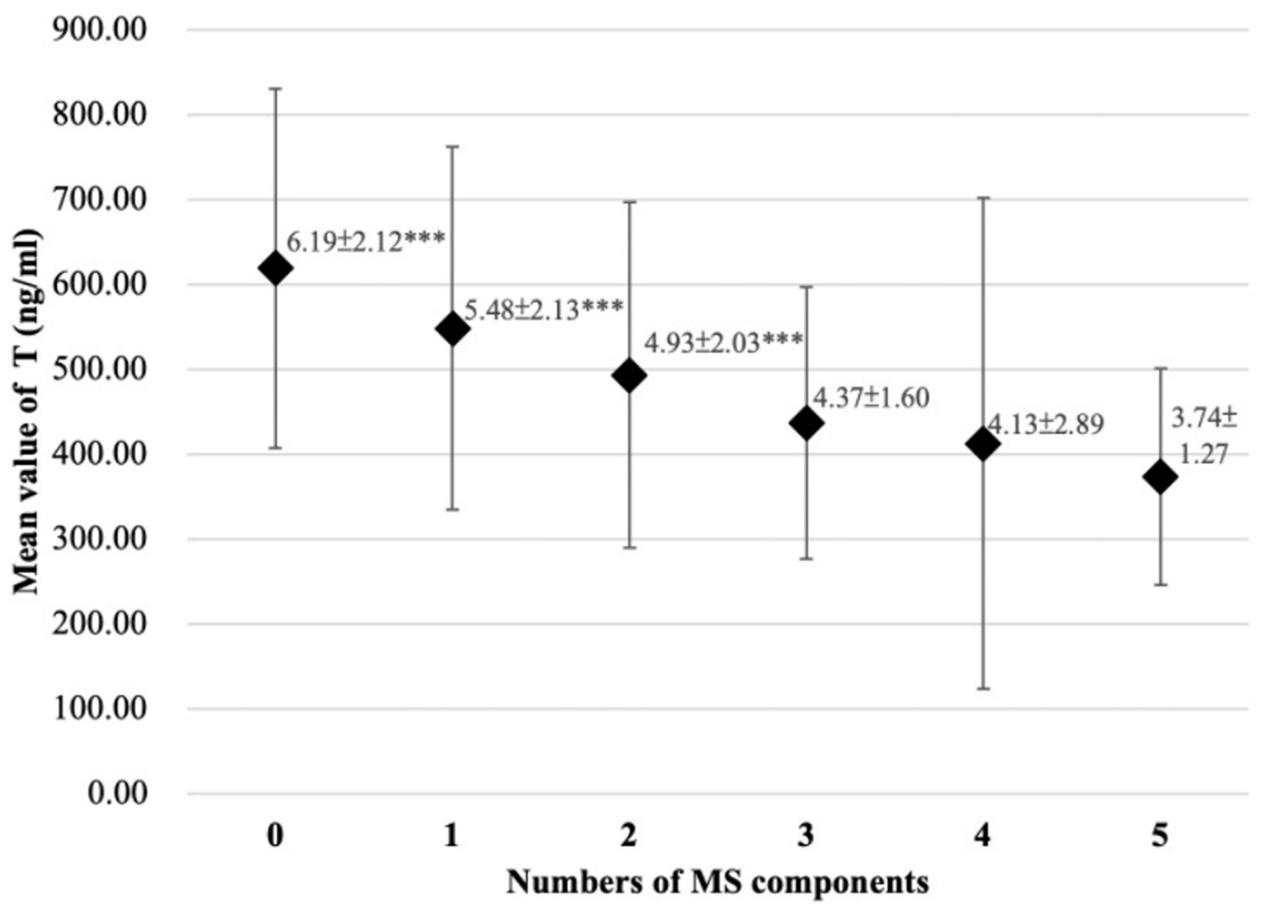

Figure I The One-way ANOVA of mean T levels between different numbers of measures that exceeds the cut-off values of MS components.

\section{Results}

Patient Characteristics of the Participants in Different Age Group with or Without MS

Basic patient characteristics are summarized in Table 1. After determining mean values of each parameter, significant differences in all, except age, were observed between the Non-MS and MS subgroups in group $2(P=0.703)$ and group $3(P=0.472)$. The MS group had significantly lower serum $\mathrm{T}$ levels compared to the non-MS group in each age group.

\section{One-Way ANOVA Analysis}

Figure 1 showed the One-way ANOVA of mean T-values between different numbers of measures that exceeds the cut-off values of MS components. The mean value of $\mathrm{T}$ was significantly higher in patients without MS component $(6.19 \pm 2.12 \mathrm{ng} / \mathrm{mL})$ than those with one-to-five MS components (with one MS component: $5.48 \pm 2.13 \mathrm{ng} / \mathrm{mL}$, two MS components: $4.93 \pm 2.03 \mathrm{ng} / \mathrm{mL}$, three MS components: $4.37 \pm 1.60 \mathrm{ng} / \mathrm{mL}$, four MS components: $4.13 \pm 2.89$ $\mathrm{ng} / \mathrm{mL}$, five MS components: $3.74 \pm 1.27 \mathrm{ng} / \mathrm{mL}$ and $P<0.001)$. The mean value of $\mathrm{T}$ in patients with one MS component is higher than those with two-to-five MS components and the $P$-value showed statistical significance $(P<0.001)$. The mean value of $\mathrm{T}$ was higher in patients with two MS components than those with three-to-five MS components and the $P$-value showed statistical significance $(P<0.001)$. There was no significant difference between the patients with three components and the patients with four or five components.

Table 2 Logistic Regression Analysis for BMI and Testosterone

\begin{tabular}{|c|c|c|c|c|c|c|c|c|}
\hline & \multirow[t]{2}{*}{ B } & \multirow[t]{2}{*}{ OR } & \multicolumn{2}{|c|}{ 95\% Cl for OR } & \multirow[t]{2}{*}{ B } & \multirow[t]{2}{*}{ OR } & \multicolumn{2}{|c|}{ 95\% Cl for OR } \\
\hline & & & Lower & Upper & & & Lower & Upper \\
\hline $\mathrm{T}$ & -0.189 & $0.828 * * *$ & 0.788 & 0.869 & -0.192 & $0.825 * * *$ & 0.785 & 0.867 \\
\hline BMI & 0.353 & $1.424 * * *$ & 1.384 & 1.465 & 0.373 & $1.452 * * *$ & 1.410 & 1.496 \\
\hline age & - & - & - & - & 0.039 & $1.040 * * *$ & 1.032 & 1.047 \\
\hline
\end{tabular}

Note: $* * * p<0.001$. 
Table 3 Logistic Regression Analysis for BMI and Testosterone and MS in Different Age Group

\begin{tabular}{|c|c|c|c|c|c|c|c|c|c|c|c|c|}
\hline & \multicolumn{4}{|c|}{ Age $<50(n=3,066)$} & \multicolumn{4}{|c|}{ Age $=50-64(n=1,384)$} & \multicolumn{4}{|c|}{$A g e \geqq 65(n=216)$} \\
\hline & \multirow[t]{2}{*}{ B } & \multirow[t]{2}{*}{ OR } & \multicolumn{2}{|c|}{$95 \% \mathrm{Cl}$ for OR } & \multirow[t]{2}{*}{ B } & \multirow[t]{2}{*}{ OR } & \multicolumn{2}{|c|}{$95 \% \mathrm{Cl}$ for OR } & \multirow[t]{2}{*}{ B } & \multirow[t]{2}{*}{ OR } & \multicolumn{2}{|c|}{$95 \% \mathrm{Cl}$ for OR } \\
\hline & & & Lower & Upper & & & & & & & Lower & Upper \\
\hline $\mathrm{T}$ & -0.211 & $0.810 * * *$ & 0.758 & 0.865 & -0.141 & $0.868 * * *$ & 0.802 & 0.940 & -0.367 & $0.693 * *$ & 0.559 & 0.858 \\
\hline BMI & 0.335 & $1.397 * * *$ & 1.351 & 1.446 & 0.438 & $1.550 * * *$ & 1.459 & 1.647 & 0.417 & $1.517 * * *$ & 1.302 & 1.768 \\
\hline
\end{tabular}

Note: $* * P<0.01 ; * * *<<0.001$.

\section{Logistic Regression Analysis for BMI and T and MS with and without Age Stratification}

The multivariable logistic regression without age stratification (Table 2) showed all the factors are statistically significant for MS (T: $\mathrm{OR}=0.825 ; 95 \% \mathrm{CI}=0.785-0.867 ; P<0.001$; BMI: $\mathrm{OR}=1.452 ; 95 \% \mathrm{CI}=1.410-1.496 ; P<0.001$; Age: $\mathrm{OR}=1.040 ; 95 \% \mathrm{CI}=1.032-1.047 ; P<0.001)$.

Logistic regression models with age stratification (Table 3 ) showed those with greater $\mathrm{T}$ had lower ORs for MS after adjusting for $\mathrm{BMI}$ in the $\geq 65$ years old group ( $\mathrm{OR}=0.693$; 95\% CI $=0.559-0.858 ; P<0.001) ; 50-64$ years old group $(\mathrm{OR}=0.868 ; 95 \% \mathrm{CI}=0.802-0.940 ; \quad P<0.001)$ and $<50$ years old group $(\mathrm{OR}=0.810 ; 95 \% \quad \mathrm{CI}=0.758-0.865$; $P<0.001)$.

\section{Discussion}

The current study found that lower T levels were strongly associated with MS in the Taiwanese population, a finding consistent with the majority of previously published studies on other ethnicities. ${ }^{11-13}$ Our data analysis showed that the value of $\mathrm{T}$ increased with age, which is contradicted with our knowledge and previous study. ${ }^{20}$ Since there is no evidence of existent testosterone therapy, this phenomenon might be the fact that those who had regular health examination care more their own health. Our research provides an Asian-based population study and enhances the feasibility of possible treatment plans within the local medical system.

MS, also called insulin resistance syndrome, is often associated with obesity, followed by the hyperinsulinemia, hyperglycemia, and dyslipidemia, eventually leading to hypertension, vascular dysfunction, and atherosclerotic cardiovascular disease. ${ }^{21}$ Studies have suggested that hypogonadism is associated with insulin resistance, thereby contributing to $\mathrm{MS},{ }^{22}$ although a definitive mechanism has yet to be determined. In 2005, hyperglycemia and insulin resistance had been observed in those receiving androgen-deprivation therapy for prostate cancer treatment. ${ }^{23}$ One animal model study revealed that $\mathrm{T}$ treatment reversed early apoptotic damage to pancreatic beta cells after streptozotocin injection in castrated rats, suggesting the protective effects of the androgen hormone in the rat pancreas. ${ }^{24}$ Another randomized control research in 2016 showed that $\mathrm{T}$ therapy increased the glucose infusion rate (regarded as insulin sensitivity) and upregulated insulin signaling genes (IR-b, IRS-1, AKT-2, and GLUT4 in adipose cells) in patients with hypogonadotropic hypogonadism. ${ }^{25}$ Moreover, one cohort study of 702 middle-aged Finnish men with 11 years of follow-up found a several-fold increase in the risk of MS among those with the lowest fourth of serum total T and SHBG concentrations, after adjusting for other common factors, including age, smoking, alcohol consumption, BMI, and waist circumference. ${ }^{26}$ Conversely, one cohort study revealed that an increase of SHBG by $17.3 \mathrm{nmol} / 1$ increased $22 \%$ of mortality in men with type 2 diabetes, suggesting the potential restraining ability of $\mathrm{SHBG}^{7}$ A plasma metabolic investigation revealed that various metabolic pathways significantly affected in insulin-resistant male hypogonadism. Moreover, the same study showed reduced GLUT4 expression in muscle and fat tissue, inefficient fatty acid usage during $\beta$ oxidation, increased lipogenesis in the liver, and increased proline and lysine accumulation, which might cause osteoporosis. ${ }^{27}$ Androgen deficiency, either iatrogenic or spontaneous, seemed to have an apparent role in further inducing metabolic abnormality.

On the other hand, adiposity itself has been a key component of MS, with the associated hyperinsulinemia also leading to low serum $\mathrm{T}$ levels through the suppression of SHBG and steroidogenesis in the testis. ${ }^{28-31}$ Accordingly, studies have shown that weight loss or weight maintenance actually increased total and free $\mathrm{T}$, as well as SHBG, in obese men. ${ }^{32}$ Furthermore, increased insulin resistance was found to be correlated with decreased testicular production of $\mathrm{T}^{30}$ All of the aforementioned research results highlight the complexity of human endocrinology and the interrelatedness of 
each component. As such, optimal medical intervention is required to cease the vicious cycle strengthened by such a phenomenon and prevent disease progression.

$T$ replacement therapy has been a widely discussed topic in recent years. The potential benefits of $\mathrm{T}$ therapy include improvements in sexual function, depressive symptoms, muscle strength, physical function, and bone minerals density. ${ }^{10}$ A systemic review of four randomized control trials, including 1,779 patients, indicated that $\mathrm{T}$ promoted significantly better sexual function and satisfaction compared to the placebo. ${ }^{33}$ However, potential risks involved with $\mathrm{T}$ treatment, including cardiovascular disease, unfavorable prostate outcomes, and erythrocytosis should always be considered on an individual level, although a large observational study found no increased risk in myocardial infarction, stroke or thrombosis, and another review even suggested reduced cardiovascular and all-cause mortality, especially in those with type 2 diabetes mellitus and MS. ${ }^{34,35}$ One metaanalysis of four randomized control trials found that $T$ replacement therapy significantly reduced fasting glucose, triglycerides, and waistline, and increased HDL levels. ${ }^{36}$ Furthermore, $\mathrm{T}$ replacement therapy was found to have a better therapeutic effect on decreasing waistline, HbAlc, and improving sexual function in patients with higher SHBG and older age in a randomized control trial. ${ }^{37}$

However, in 2015, the US Food and Drug Administration still recommended the use $\mathrm{T}$ therapy only for classic hypogonadism but not for aged-related decline due to the lack of established efficacy and weak evidence on cardiovascular risk. $^{38}$ Though no definitive conclusions had been established, one double-blind, placebo-controlled study found similar adverse events, including an increase in prostate-specific antigen level, prostate cancer, cardiovascular events, and erythrocytosis, during the first year of the trial in the treatment and placebo groups. ${ }^{39}$ Moreover, the 2018 Endocrine Society Clinical Practice Guideline has recommended therapy only in patients with $\mathrm{T}$ deficiency-induced symptoms and signs, among which MS was not included. ${ }^{10}$ Meanwhile, the latest (2020) American College of Physicians guideline on T usage has recommended medical intervention exclusively in patients asking to be treated for age-related low $\mathrm{T}$ level with sexual dysfunction. ${ }^{17}$ Specifically, studies have presented inconsistent results regarding the association between type 2 diabetes mellitus and hypogonadism and the efficacy of $\mathrm{T}$ replacement therapy. ${ }^{10,13,16,25,40,41}$ Overall, evidence regarding the benefits of T replacement therapy for aging-related decline in $\mathrm{T}$ has still been considered insufficient, with no current clinical guideline approving its feasibility considering its potential side-effects.
The limitation of our study included, firstly, the cross-sectional design. As such, despite observing an association between low $\mathrm{T}$ and MS among the Asian population, causality could not be clarified. Secondly, given the fact that the health examination of the MJ Health Screening Center is self-paid, we might have a biased population sample regarding the income level. Thirdly, one review recently discussed the intertwined relationship between the diet, physical activity, alcohol and tobacco exposure, drug use, genetics, SHBG and metabolic status, some of which even have transgenerational effects. ${ }^{42}$ Those confounding factors are also influential on the development of metabolic disease besides merely hypogonadism and diabetes, which might be insufficient in our study. Since SHBG was not a common item in the health checkup in Taiwan and not provided by the MJ Health Screening Center, we failed to collect and analyze it in this retrospective study. Finally, in the United Kingdom, with a high percentage of immunoassays, considerable variation was noted in testosterone measurement and required further work to achieve standardization. ${ }^{43}$

The current geriatrics practice in Taiwan has yet to include $\mathrm{T}$ during routine health examination. Therefore, the current study suggests incorporating $\mathrm{T}$ in the examination list for men, especially those over 65 years old. Despite the lack of current recommendations for $\mathrm{T}$ treatment for hypogonadism in men, determining $\mathrm{T}$ levels can be a relatively simple and cost-effective method for predicting the risk of MS and will surely provide an another viewpoint in the standard of chronic diseases prevention. The results of this study also provide individual recommendations for male patients across different ages.

\section{Conclusion}

The current study showed that lower serum $\mathrm{T}$ was highly associated with MS, with the predictive value of serum $\mathrm{T}$ increasing with age (age $\geq 65$ years old) in Taiwanese men.

\section{Abbreviations}

$\mathrm{T}$, testosterone; HIS, hypogonadism in males; SHBG, sex hormone-binding globulin; MS, metabolic syndrome; AHA/NHLBI, American Heart Association/National Heart, Lung, and Blood Institute; FBS, fasting blood sugar; HDL, high-density lipoprotein; TG, triglycerides; SBP, systolic blood pressure; CIs, confidence intervals; BMI, body mass index; ORs, odds ratios. 


\section{Ethics and Informed Consent}

The study was approved by the Tri-Service General Hospital Institutional Review Board (TSGHIRB number: A202005160) and conducted in accordance with the principles stated in the Declaration of Helsinki. All participants in the research were given the written informed consent before the health examination to authorize the data analysis. Personal identification data was removed in the MJ Health Research Foundation, so the participants remained anonymous during the whole research process. All or part of the data used in this research were authorized by and received from MJ Health Research Foundation (Authorization Code: MJHRF2019016A). All data accessed complied with relevant data protection and privacy regulations. The detail of the study population and data collection were described and reported elsewhere. ${ }^{18}$

\section{Acknowledgments}

This study received assistance of the Department of Medical Education and Research, Taichung Armed Forces General Hospital. All or part of the data used in this research were authorized by, and received from MJ Health Research Foundation (Authorization Code: MJHRF2019016A). Any interpretation or conclusion described in this paper does not represent the views of MJ Health Research Foundation.

\section{Funding}

We didn't receive any funding support in this work.

\section{Disclosure}

The authors report no conflicts of interest in this work.

\section{References}

1. Davidiuk AJ, Broderick GA. Adult-onset hypogonadism: evaluation and role of testosterone replacement therapy. Transl Androl Urol. 2016;5(6):824. doi:10.21037/tau.2016.09.02

2. Khera M, Broderick GA, Carson III CC, et al. Adult-onset hypogonadism. Mayo Clinic Proceedings; Elsevier. 2016;91(7) doi:10.1016/j.mayocp.2016.04.022

3. Mulligan T, Frick M, Zuraw Q, Stemhagen A, McWhirter C. Prevalence of hypogonadism in males aged at least 45 years: the HIM study. Int $J$ Clin Pract. 2008;60(7):762-769. doi:10.1111/ j.1742-1241.2006.00992.x

4. Araujo AB, Esche GR, Kupelian V, et al. Prevalence of symptomatic androgen deficiency in men. $J$ Clin Endocrinol Metab. 2007;92 (11):4241-4247. doi:10.1210/jc.2007-1245

5. Wu FC, Tajar A, Pye SR, et al. Hypothalamic-pituitary-testicular axis disruptions in older men are differentially linked to age and modifiable risk factors: the European Male Aging Study. J Clin Endocrinol Metab. 2008;93(7):2737-2745. doi:10.1210/jc.2007-1972
6. Le TN, Nestler JE, Strauss III JF, Wickham III EP. Sex hormone-binding globulin and type 2 diabetes mellitus. Trends Endocrinol Metab. 2012;23(1):32-40. doi:10.1016/j.tem.2011.09.005

7. Tint AN, Hoermann R, Wong $\mathrm{H}$, et al. Association of sex hormone-binding globulin and free testosterone with mortality in men with type 2 diabetes mellitus. Eur J Endocrinol. 2016;174 (1):59-68. doi:10.1530/EJE-15-0672

8. Park Y-W, Zhu S, Palaniappan L, Heshka S, Carnethon MR, Heymsfield SB. The metabolic syndrome: prevalence and associated risk factor findings in the US population from the third national health and nutrition examination survey, 1988-1994. Arch Intern Med. 2003;163(4):427-436. doi:10.1001/archinte.163.4.427

9. Aguilar M, Bhuket T, Torres S, Liu B, Wong RJ. Prevalence of the metabolic syndrome in the United States, 2003-2012. JAMA. 2015;313(19):1973-1974. doi:10.1001/jama.2015.4260

10. Bhasin S, Brito JP, Cunningham GR, et al. Testosterone therapy in men with hypogonadism: an endocrine society clinical practice guideline. J Clin Endocrinol Metab. 2018;103(5):1715-1744. doi:10.1210/jc.2018-00229

11. Kelly DM, Jones TH. Testosterone: a metabolic hormone in health and disease. J Endocrinol. 2013;217(3):R25-45. doi:10.1530/JOE-12-0455

12. Cunningham GR. Testosterone and metabolic syndrome. Asian $J$ Androl. 2015;17(2):192. doi:10.4103/1008-682X.148068

13. Harada N. Role of androgens in energy metabolism affecting on body composition, metabolic syndrome, type 2 diabetes, cardiovascular disease, and longevity: lessons from a meta-analysis and rodent studies. Biosci Biotechnol Biochem. 2018;82(10):1667-1682. doi:10.1080/09168451.2018.1490172

14. Corona G, Rastrelli G, Maggi M. Diagnosis and treatment of late-onset hypogonadism: systematic review and meta-analysis of TRT outcomes. Best Pract Res Clin Endocrinol Metab. 2013;27 (4):557-579. doi:10.1016/j.beem.2013.05.002

15. Wan Z-H, Wen Y-B, Ding Q-F, Xu T-Y. Effects of testosterone substitution on metabolic syndrome-related factors in hypogonadal males: a meta-analysis. Zhonghua Nan Ke Xue. 2010;16(6):510-515.

16. Grossmann M, Hoermann R, Wittert G, Yeap BB. Effects of testosterone treatment on glucose metabolism and symptoms in men with type 2 diabetes and the metabolic syndrome: a systematic review and meta-analysis of randomized controlled clinical trials. Clin Endocrinol (Oxf). 2015;83(3):344-351. doi:10.1111/cen.12664

17. Qaseem A, Horwitch CA, Vijan S, Etxeandia-Ikobaltzeta I, Kansagara D. Testosterone treatment in adult men with age-related low testosterone: a clinical guideline from the American College of Physicians. Ann Intern Med. 2020;172(2):126-133. doi:10.7326/M19-0882

18. Wu X, Tsai SP, Tsao CK, et al. Cohort profile: the Taiwan MJ Cohort: half a million Chinese with repeated health surveillance data. Int $J$ Epidemiol. 2017;46(6):1744-1744g. doi:10.1093/ije/dyw282

19. Grundy SM, Cleeman JI, Daniels SR, et al. Diagnosis and management of the metabolic syndrome: an American Heart Association/National Heart, Lung, and Blood Institute scientific statement. Circulation. 2005;112 (17):2735-2752. doi:10.1161/CIRCULATIONAHA.105.169404

20. Harman SM, Metter EJ, Tobin JD, Pearson J, Blackman MR. Longitudinal effects of aging on serum total and free testosterone levels in healthy men. J Clin Endocrinol Metab. 2001;86(2):724-731. doi:10.1210/jcem.86.2.7219

21. DeFronzo RA, Ferrannini E. Insulin resistance: a multifaceted syndrome responsible for NIDDM, obesity, hypertension, dyslipidemia, and atherosclerotic cardiovascular disease. Diabetes Care. 1991;14 (3):173-194. doi:10.2337/diacare.14.3.173

22. Traish AM, Saad F, Guay A. The dark side of testosterone deficiency: II. Type 2 diabetes and insulin resistance. J Androl. 2008;30 (1):23-32. doi:10.2164/jandrol.108.005751

23. Basaria S, Muller DC, Carducci MA, Egan J, Dobs AS. Hyperglycemia and insulin resistance in men with prostate carcinoma who receive androgen-deprivation therapy. Cancer. 2006;106 (3):581-588. doi:10.1002/cncr.21642 
24. Morimoto S, Mendoza-Rodriguez C, Hiriart M, Larrieta M, Vital P, Cerbon M. Protective effect of testosterone on early apoptotic damage induced by streptozotocin in rat pancreas. J Endocrinol. 2005;187(2):217-224. doi:10.1677/joe.1.06357

25. Dhindsa S, Ghanim H, Batra M, et al. Insulin resistance and inflammation in hypogonadotropic hypogonadism and their reduction after testosterone replacement in men with type 2 diabetes. Diabetes Care. 2016;39(1):82-91. doi:10.2337/dc15-1518

26. Laaksonen DE, Niskanen L, Punnonen K, et al. Testosterone and sex hormone-binding globulin predict the metabolic syndrome and diabetes in middle-aged men. Diabetes Care. 2004;27(5):1036-1041. doi:10.2337/diacare.27.5.1036

27. Gevi F, Fanelli G, Zolla L. Metabolic patterns in insulin-resistant male hypogonadism. Cell Death Dis. 2018;9(6):1-11. doi:10.1038/ s41419-018-0587-9

28. Glass AR, Swerdloff RS, Bray GA, Dahms WT, Atkinson RL. Low serum testosterone and sex-hormone-binding-globulin in massively obese men. J Clin Endocrinol Metab. 1977;45(6):1211-1219. doi:10.1210/jcem-45-6-1211

29. Kaufman JM, Vermeulen A. The decline of androgen levels in elderly men and its clinical and therapeutic implications. Endocr Rev. 2005;26(6):833-876.

30. Pitteloud N, Hardin M, Dwyer AA, et al. Increasing insulin resistance is associated with a decrease in Leydig cell testosterone secretion in men. J Clin Endocrinol Metab. 2005;90(5):2636-2641. doi:10.1210/ jc. 2004-2190

31. Saad F, Gooren L. The role of testosterone in the metabolic syndrome: a review. J Steroid Biochem Mol Biol. 2009;114(1-2):40-43. doi:10.1016/j.jsbmb.2008.12.022

32. Kaukua J, Pekkarinen T, Sane T, Mustajoki P. Sex hormones and sexual function in obese men losing weight. Obes Res. 2003;11 (6):689-694. doi:10.1038/oby.2003.98

33. Ponce OJ, Spencer-Bonilla G, Alvarez-Villalobos N, et al. The efficacy and adverse events of testosterone replacement therapy in hypogonadal men: a systematic review and meta-analysis of randomized, placebo-controlled trials. J Clin Endocrinol Metab. 2018;103 (5):1745-1754. doi:10.1210/jc.2018-00404
34. Shores MM. Testosterone treatment and cardiovascular events in prescription database studies. Asian J Androl. 2018;20(2):138. doi:10.4103/aja.aja_25_17

35. Hackett G. Metabolic effects of testosterone therapy in men with type 2 diabetes and metabolic syndrome. Sex Med Rev. 2019;7 (3):476-490. doi:10.1016/j.sxmr.2018.12.004

36. Corona G, Monami M, Rastrelli G, et al. Testosterone and metabolic syndrome: a meta-analysis study. J Sex Med. 2011;8(1):272-283. doi:10.1111/j.1743-6109.2010.01991.x

37. Ramachandran S, Hackett GI, Strange RC. Testosterone replacement therapy: pre-treatment sex hormone binding globulin levels and age may identify clinical subgroups. Andrology. 2020;8(5):1222-1232. doi:10.1111/andr.12813

38. Nguyen CP, Hirsch MS, Moeny D, Kaul S, Mohamoud M, Joffe HV. Testosterone and "age-related hypogonadism"-FDA concerns. $N$ Engl J Med. 2015;373(8):689-691. doi:10.1056/NEJMp1506632

39. Snyder PJ, Bhasin S, Cunningham GR, et al. Effects of testosterone treatment in older men. $N$ Eng $J$ Med. 2016;374(7):611-624. doi:10.1056/NEJMoa1506119

40. Gianatti EJ, Dupuis P, Hoermann R, et al. Effect of testosterone treatment on glucose metabolism in men with type 2 diabetes: a randomized controlled trial. Diabetes Care. 2014;37(8):2098-2107. doi:10.2337/dc13-2845

41. Mohler III ER, Ellenberg SS, Lewis CE, et al. The effect of testosterone on cardiovascular biomarkers in the testosterone trials. J Clin Endocrinol Metab. 2018;103(2):681-688. doi:10.1210/jc.2017-02243

42. Crisóstomo L, Pereira SC, Monteiro MP, Raposo JF, Oliveira PF, Alves MG. Lifestyle, metabolic disorders and male hypogonadism-A one-way ticket? Mol Cell Endocrinol. 2020;110945.

43. Livingston M, Downie P, Hackett G, Marrington R, Heald A, Ramachandran S. An audit of the measurement and reporting of male testosterone levels in UK clinical biochemistry laboratories. Int J Clin Pract. 2020;e13607.

Diabetes, Metabolic Syndrome and Obesity: Targets and Therapy

\section{Publish your work in this journal}

Diabetes, Metabolic Syndrome and Obesity: Targets and Therapy is an international, peer-reviewed open-access journal committed to the rapid publication of the latest laboratory and clinical findings in the fields of diabetes, metabolic syndrome and obesity research. Original research, review, case reports, hypothesis formation, expert opinion and commentaries are all considered for publication. The manuscript management system is completely online and includes a very quick and fair peer-review system, which is all easy to use. Visit http://www.dovepress.com/testimonials.php to read real quotes from published authors.

Submit your manuscript here: https://www.dovepress.com/diabetes-metabolic-syndrome-and-obesity-targets-and-therapy-journal 